\title{
A longitudinal study on the relationship between mother's personality trait and eating behaviors, food intake, maternal weight gain during pregnancy and neonatal birth weight
}

Mahboobeh Shakeri ${ }^{1,2}$, Sima Jafarirad ${ }^{1,2^{*}}$ (D), Reza Amani ${ }^{3,4}$, Bahman Cheraghian $^{5}$ and Mahin Najafian ${ }^{6}$

\begin{abstract}
Background: Many factors such as social and behavioral are related to appropriate weight gain during pregnancy, and there is much of importance to find them. The aim of the study was to explore the association of personality traits, with eating behaviors, food intake, maternal weight gain during pregnancy as well as the neonatal birth weight.

Methods: This is a longitudinal and cross-sectional study. Eating behaviors were assessed using the Dutch Eating Behavior Questionnaire (DEBQ), and the NEO personality inventory was used to assess personality in pregnant subjects. A validated food frequency questionnaire was used to determine food intake. Three hundred and sixty pregnant subjects from Ahvaz (the capital city of Khuzestan province, Iran) were followed from the 20th week of pregnancy until delivery.

Results: High neuroticism was associated with higher consumption of highly energetic foods $(p<0.05)$ and less consumption of vegetables $(p<0.01)$, also was related with lower weight gain during pregnancy and neonatal birth weight $(p<0.05)$. Openness to experience, extraversion and agreeableness were linked with higher consumption of vegetables $(p<0.05)$. Conscientiousness predicted lower neonatal weight (odds ratio: 1.20, confidence interval: $1.07-1.34, p<0.01)$.
\end{abstract}

Conclusions: Identification of personality traits would help to change the lifestyle and improve management guidelines.

Keywords: Pregnancy, Personality traits, Eating behavior, Food intake, Gestational weight gain, Birth weight

\footnotetext{
* Correspondence: Jafarirad-s@ajums.ac.ir; sjafarirad@gmail.com

${ }^{1}$ Nutrition and Metabolic Diseases Research Center, Ahvaz Jundishapur University of Medical Sciences, Ahvaz, Iran

${ }^{2}$ Department of Nutrition, School of Allied Medical Sciences, Ahvaz Jundishapur University of Medical Sciences, Ahvaz, Iran

Full list of author information is available at the end of the article
}

(c) The Author(s). 2020 Open Access This article is licensed under a Creative Commons Attribution 4.0 International License, which permits use, sharing, adaptation, distribution and reproduction in any medium or format, as long as you give appropriate credit to the original author(s) and the source, provide a link to the Creative Commons licence, and indicate if changes were made. The images or other third party material in this article are included in the article's Creative Commons licence, unless indicated otherwise in a credit line to the material. If material is not included in the article's Creative Commons licence and your intended use is not permitted by statutory regulation or exceeds the permitted use, you will need to obtain permission directly from the copyright holder. To view a copy of this licence, visit http://creativecommons.org/licenses/by/4.0/ The Creative Commons Public Domain Dedication waiver (http://creativecommons.org/publicdomain/zero/1.0/) applies to the data made available in this article, unless otherwise stated in a credit line to the data. 


\section{Background}

According to previous studies, there is a relationship between personality traits and various health issues, such as cardiovascular diseases, high blood pressure, diabetes, gastroenterological complaints $[1,2]$, inflammatory responses [3, 4] and general health condition [5]. It is often assumed that the relationships between personality traits and well-being are due to some health-related behaviors such as dietary habits and various other unhealthy behaviors [2, 6, 7], for example, smoking [8], alcohol consumption [9], drug abuse [10], lack of physical exercise [11], and a number of other behaviors that influence the health [12].

Personality traits can influence lifestyle, cognition, motivation, and behavior in various conditions [13]. Understanding personality traits is important for maintaining health. The Five-Factor Model (FFM) is often used for the assessment of personality traits [14]. This model has been validated in many studies in different cultures by using different assessment tools [15-17]. FFM distinguishes five dimensions of personality: Neuroticism, Extraversion, Openness, Agreeableness, and Conscientiousness [18]. A study showed subjects with higher body mass index (BMI) had lower scores on conscientiousness or higher scores on extraversion or neuroticism personality traits. A similar relationship was also shown for body fat, as well as waist, and hip circumference [7]. Other studies consider neuroticism as a risk factor for obesity and showed protective effect of conscientiousness toward weight gain [19].

Various mechanisms contribute to the relationship between personality and body weight, which include cognitive, behavioral, physiological and psychological pathways [12]. In recent studies, personality traits have been found to be correlated with eating behaviors. Some studies have shown that the personality types may affect eating behaviors which, in turn, affect choices of food intake [20, 21]. It is clear that inappropriate food choices and eating habits are related to obesity and weight gain [22] and controlling them may lead to proper weight management.

Maternal health, influences neonatal well-being. Maternal weight before and during pregnancy may influence the course of the pregnancy, fetal development, and the child's health in both early and adult lives. A study that was conducted in Iran, showed inappropriate food intake among most of the pregnant women; however intake of different food groups had no relationship with weight gain during pregnancy [23]. The Institute of Medicine (IOM) has determined optimal range of weight gain during pregnancy based on women's pre-pregnancy BMI [24]. Currently, less than one third of pregnant women have optimal weight gain during pregnancy and most of them gain excess weight [25, 26]. In this regard, a study in Iran confirmed pre-pregnancy BMI as a predictor of weight gain and found some socio-economic factors related to maternal weight gain, but psychological factors were not investigated [23]. A better understanding of factors related to inappropriate weight gain during pregnancy is necessary. The relationship between personality traits and weight gain, diet and eating behaviors of pregnant women has remained unknown. Finding the relationship between these items helps nutritional consultants to improve maternal education, especially in developing countries. To the best of our knowledge, no studies have investigated the effect of personality traits on dietary intakes and weight gain during pregnancy [27]. Therefore, this study was conducted in Iran to evaluate the association of mother's personality trait with eating behaviors, food intake, maternal weight gain, and neonatal birth weight.

\section{Methods \\ Study design}

This study was a longitudinal and cross-sectional survey. All pregnant women were recruited at the second half of pregnancy period and were followed until delivery.

\section{Participants and recruitment}

This study was conducted in Ahvaz, a city in South of Iran. Subjects were recruited from healthy pregnant women referred to Kurosh and Saa'di health centers, respectively representative of health centers in east and west of Ahvaz. The inclusion criteria were 18-45 years of age at the expected date of delivery, and subjects being at the 20th-22nd gestational weeks. Since many pregnant woman experience morning sickness during the first months of pregnancy which may continue up to 3rd or 4th months, we decided to use the second half of pregnancy for the study protocol with the other reason being that most of the maternal weight gain occurs in the second half of pregnancy. Exclusion criteria were as follows: those having chronic infectious diseases, metabolic disorders, gestational diabetes, gestational hypertension, pre-eclampsia, eclampsia, twin pregnancy, preterm delivery, eating disorders (anorexia, bulimia), and emotional disorders (depression, stress and anxiety). In the first half of the pregnancy (the first 20 weeks), psychiatric evaluation is performed routinely using the Kessler Psychological Distress Scale (K10), for determination of depression and anxiety.

The sample size was calculated based on the relationship between personality traits of adults and BMI 
[28]. The following formula was used to calculate sample size. The correlation coefficient $(\mathrm{r}), \alpha$, and $\beta$ were $0.17,0.05$ and 0.1 respectively. $n=\left[\frac{z_{1-\frac{\alpha}{2}}+z_{1-\beta}}{C}\right]^{2}$, $C=0.5[\ln (1+r) /(1-\mathrm{r})]$.

Considering the inclusion criteria and the calculated sample size, 360 pregnant women participated in the study.

\section{Instruments}

Three valid and reliable questionnaires, (NEO Five-Factor Inventory, Dutch eating behavior questionnaire and a semi-quantitative food frequency questionnaire) were used to evaluate personality traits, eating behavior and food intake of participants respectively. All questionnaires were completed by trained interviewers at the first visit (after recruitment to the study). The interviewers explained about the questionnaires to the participants, before asking them to complete the questionnaires, also checked and resolved any vague recalls.

\section{Personality traits questionnaire}

NEO Five-Factor Inventory (NEO-FFI) by McCrae and Costa [15] was used to measure FFM personality domains. NEO-FFI is one of the most widely-used instruments to describe individual differences in five domains of personality traits (Neuroticism, Extraversion, Openness to Experience, Agreeableness, and Conscientiousness). Neuroticism is the tendency to experience negative emotions (anxiety, anger, and depression). Extravert people are active, sociable, and they search for stimulation. People with the Openness trait are unconventional, imaginative, creative, and artistically sensitive. Agreeableness is the tendency to be altruistic, trusting, modest, and cooperative. Conscientiousness individuals are strong-willed, reliable, persistent, and complying with rules and ethical principles [29].

\section{Eating behavior questionnaire}

Eating behaviors (restrained, emotional and external) were assessed using the Dutch eating behavior questionnaire (DEBQ) which has 33-items [30]. Ten items are included in the restraint scale which measures intentional restriction of eating in order to reduce or maintain weight. The DEBQ includes 13 items to evaluate the emotional scale and assesses eating due to emotional disorders such as anger, fear or anxiety, and not the physiological hunger. The DEBQ external scale (10 items) measures eating in response to external food-related stimuli, regardless of the internal state of hunger or satiety.

\section{Food intake questionnaire}

The whole diet was assessed using a validated and reliable semi-quantitative food frequency questionnaire (FFQ) that has been designed according to Iranian food guide pyramid [31]. The questionnaire included common foods typically consumed by Iranians. The standard serving sizes were defined in the questionnaire. Participants reported their average frequency of food intake over the past year. The frequency of intake was marked as times per day (e.g. bread), week (e.g. cheese), or month (e.g. fish). In addition, participants reported the serving size. The food frequency recall bias was limited by showing the participants the photographs of various portions and household or standard units. After completing the FFQ, the serving size was converted to grams and the reported amount of each food was converted to a daily intake value [32]. This questionnaire consisted of 45 food items. Some common foods in this questionnaire are as follows: milk, yoghurt, doogh (traditional yoghurt drink), ice cream and cheese consumption were considered in milk and dairy products group; red meat, poultry, fish, egg and legumes as proteins group; bread, rice and pasta as grains group; jam, confection, sugar, and soft drinks as sweets group; and fast foods, butter and oils as fats group.

\section{Anthropometric assessment}

Anthropometric indices, including weight gain during the second half of pregnancy as well as the infant's weight, were measured by trained research staff and recorded in individual health cases. These data were collected from the health cases in health centers. The required amount of weight gain during pregnancy was determined according to the BMI before pregnancy (the weight before pregnancy was collected from the health case of mothers by self-report. The prepregnancy weight had been written in the first weeks of pregnancy, so mothers could recall their weight before pregnancy). The final subjects' weight were taken at 38 th week of gestation. Gestational weight gain was considered adequate in the second and third trimesters if the woman was within the range recommended by IOM based on pre-pregnancy BMI. According to IOM recommendation, the rate of weight gain during second and third trimesters for low and normal pre-pregnancy BMI was $0.5 \mathrm{~kg}$ and $0.4 \mathrm{~kg}$ per week, respectively. If prepregnancy BMI was between $>26.0-29.0 \mathrm{~kg} / \mathrm{m}^{2}$, the recommended weight gain was $0.3 \mathrm{~kg} /$ week. For prepregnancy BMI more than 29, the rate of weight gain during second and third trimesters were not specified but the recommendation was that total weight gain must be less than $7.5 \mathrm{~kg}$ [24]. 


\section{Data analysis}

Statistical analysis was performed with SPSS version 17.0 software. Data were expressed as means \pm standard deviation (SD) for continuous variables or number (percentage) for categorical variables. The normality of data was analyzed using kolmongrov-smirnov test. Pearson correlation test was used to analyze the relationships between the personality traits, and eating behavior, food intake and anthropometric measurements. The One-way analysis of variances (ANOVA) was used to compare the mean of eating behaviors' score, gestational weight gain, and birth weight of infants among different tertiles of personality traits' score. Tukey test was used to compare which means differ from the rest. If distribution was not normal, related non-parametric test was used. Analysis of covariance was used to control the potential effect of some covariates such as length of gestation, pre-pregnancy BMI and maternal age. Predicting gestational weight gain and birth weight of infants by personality traits, eating behaviors and food intakes were analyzed using multinomial logistic regression. Reference group was considered adequate for both gestational weight gain and infant birth weight. For gestational weight gain, subjects' weight gain were considered adequate if they were in line with IOM recommendation (mentioned in the previous section). Also birth weight between 2500 and $4000 \mathrm{~g}$ was considered adequate.

\section{Results}

Figure 1 shows the subjects' enrollment and follow-up for the study. In total, 360 women were included in the analysis. The characteristics of these women are described in (Table 1).

\section{Bivariate correlation}

Pregnancy weight gain had positive correlation with birth weight of infants $(p<0.001)$. Pearson correlations suggest that personality factors are significantly correlated with eating behaviors and women's dietary food intakes. Only the correlations between personality traits and eating behaviors and food groups were mentioned in (Table 2) to avoid its expansion.

Neuroticism personality trait had a significant positive correlation with the consumption of ice cream ( $p=$ 0.001 ) and sweets but a significant negative correlation with the consumption of vegetables.

Extraversion had a significant positive correlation with restrained, external and emotional eating behavior as well as frequency intake of vegetables, fish ( $p=$ $0.023)$, legumes and eggs $(p=0.001)$, but had a significant negative correlation with fast food $(p<0.001)$ and red meat $(p=0.001)$ consumption. Openness to experience showed significant positive correlation with restrained, external and emotional eating behavior and frequency intake of vegetables, dairy products, and legumes $(p=0.001)$. However, it negatively correlated with the consumption of red meat $(p=0.024)$. Agreeableness had significant positive correlation with the frequency intake of vegetables and fish $(p=0.023)$ but was found to correlate negatively with the frequency intake of dairy products and ice cream $(p=$ 0.01). Conscientiousness had a significant positive correlation with restrained, external and emotional eating behavior and the frequency intake of fruits, vegetables, legumes, and eggs $(p=0.001)$ but a negative correlation with frequency intake of red meat $(p=0.001)$ and confections $(p=0.002)$.

\section{Comparison of eating behaviors between levels of personality traits}

The analysis of variance was used to examine the associations between personality traits and eating behavior, weight gain in pregnancy both in the second half and throughout the whole pregnancy period, and birth weight of infants. Emotional eating behavior of women with high neuroticism was significantly higher than those with moderate neuroticism $(p=0.02)$; and women with high neuroticism compared to moderate and low neuroticism gained significantly higher scores of external eating behavior $(p<0.001)$.

Women with moderate extraversion had significantly lower score of restrained eating compared to low and high scores of extraversion $(p<0.001)$; subjects with higher extraversion had higher scores of emotional eating behavior $(p<0.001)$.

Individuals with high openness to experience had significantly higher restrained, emotional and external eating scores compared to those with low or moderate openness $(p<0.001)$.

Women who scored high in conscientiousness were significantly higher in restrained eating behavior compared to the moderate group $(p<0.001)$. However, high conscientiousness women had higher scores of emotional and external eating behavior compared to women in low and moderate groups, respectively $(p=0.001)$. The results were shown in (Table 3).

\section{Comparison of birth weight in relation to levels of personality traits}

Neonatal birth weight was lower in women with high neuroticism in contrast to those with moderate neuroticism $(p=0.017)$. Also, a significant difference was found in birth weight between women with low and high conscientiousness $(p<0.001)$, as well as moderate and high conscientiousness $(p=0.034)$, which means neonatal birth weight among women with high conscientiousness 


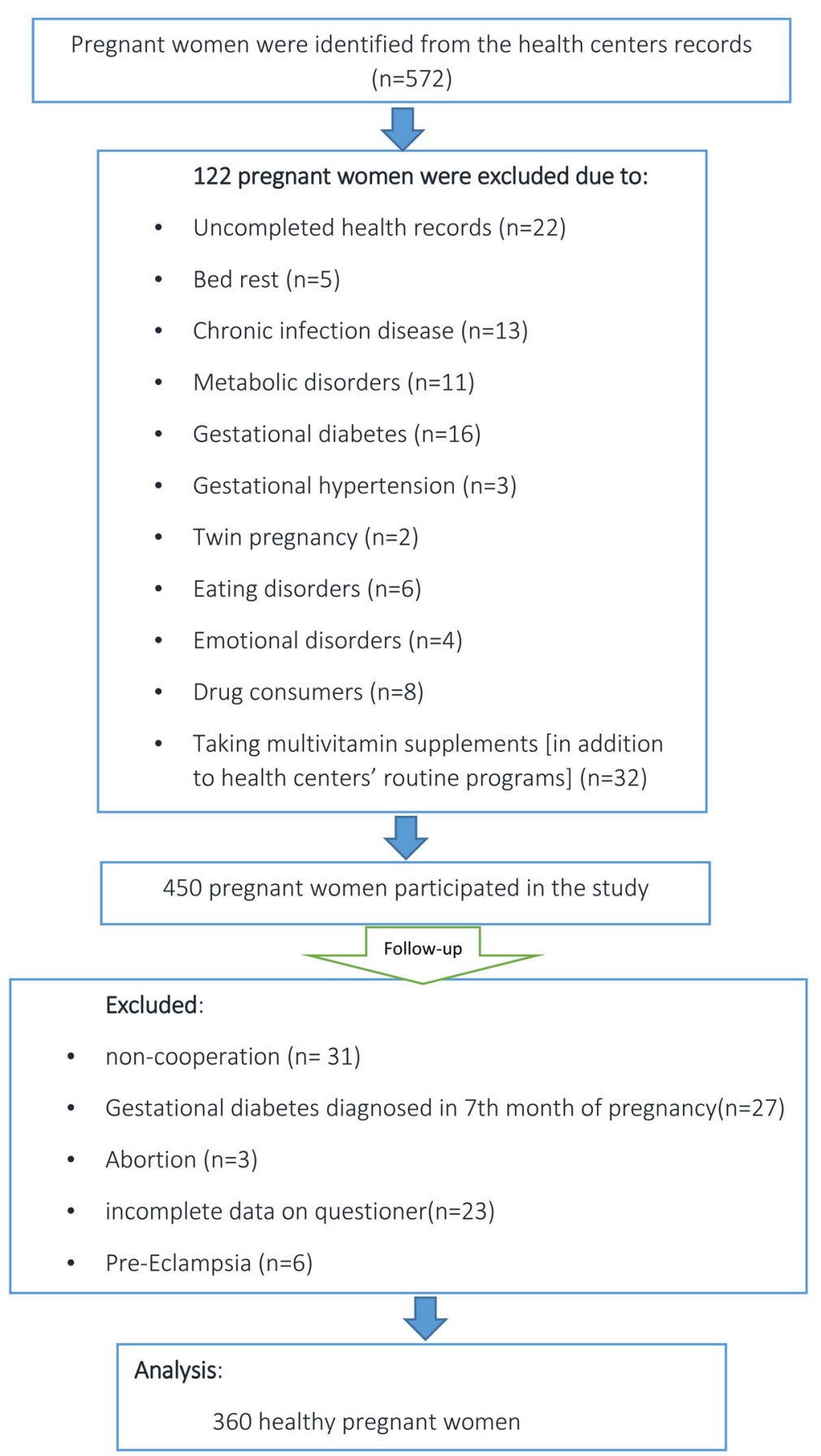

Fig. 1 The flowchart of recruitment and follow-up of pregnant women

was lower than women with low or moderate conscientiousness (Table 3).

Associations between personality traits, eating behaviors, food intake, and gestational weight gain

The multinomial logistic regression analysis was used to determine if personality traits, eating behaviors, or frequency intake of foods could predict gestational weight gain and neonatal birth weight.

The reference group for total weight gain, the second half of pregnancy weight gain, and neonatal birth weight was considered 'adequate'. Table 4 shows the outputs of 'insufficient' compared to 'adequate'. The outputs of 'excessive' compared to 'adequate' were not 
Table 1 Descriptive results for study population, demographics, personality traits, eating behaviors, dietary intake, weight gain and neonatal birth weight $(n=360)$

\begin{tabular}{ll}
\hline Variables & Mean \pm SD \\
\hline Age (year) & $28.46 \pm 5.14$ \\
Pre-pregnancy BMI $\left(\mathrm{kg} / \mathrm{m}^{2}\right)$ & $25.33 \pm 3.7$ \\
Personality traits (score) & \\
$\quad$ Neuroticism & $33.6 \pm 6.16$ \\
Extraversion & $40.5 \pm 4.35$ \\
Openness & $36.16 \pm 3.37$ \\
Agreeableness & $41.5 \pm 3.48$ \\
Conscientiousness & $41.15 \pm 2.84$ \\
Eating behavior (score) & \\
Restrained eating & $2.40 \pm 0.5$ \\
Emotional eating & $2.44 \pm 0.5$ \\
External eating & $2.33 \pm 0.52$ \\
Dietary food (serving/day) & \\
Grains & $12 \pm 3.6$ \\
Dairy products & $5.13 \pm 1.95$ \\
Proteins & $4.04 \pm 1.68$ \\
Fruits & $3.45 \pm 1.09$ \\
Vegetables & $2.09 \pm 0.95$ \\
Total weight gain (kg) & $12.7 \pm 3.2$ \\
Second half of pregnancy weight gain (kg) & $11.28 \pm 3.27$ \\
\hline Birth weight (kg) & $3.1 \pm 0.47$ \\
\hline
\end{tabular}

shown in the table due to the very low relation between them.

The results of this table showed that women with extraversion were more likely to have insufficient weight gain during the second half of pregnancy.
The emotional eating behavior was associated with insufficient weight gain as well as low birth weight infants.

Subjects with increased frequency intake of fats and decreased vegetables were more likely to have insufficient weight gain.

\section{Associations between personality traits, eating behaviors,} food intake, and birth weight

The risk of low birth weight infants was increased in pregnant women who had high scores in conscientiousness levels. This means that higher scores of conscientiousness was related to lower neonatal birth weight and that lower intake of vegetables could increase the chance of lower birth weight (Table 4).

\section{Discussion}

The present study was conducted to examine the relationship between personality traits, eating behavior, dietary food intake, gestational weight gain and neonatal birth weight.

\section{Personality trait, eating behavior, food intake and gestational weight gain}

In the current study, we tried to find associations between personality traits, eating behaviors, and dietary intakes with oscillations in weight during pregnancy in a longitudinal relation. Most pervious researches had focused exclusively on the relation between personality and BMI (primarily self-reported weights) [7, 21, 33]. Although weight gain during pregnancy occurs gradually, some individual differences may affect the rate and magnitude of weight gain. The results of our study revealed associations of extraversion, neuroticism and conscientiousness with weight gain during pregnancy. Extraversion predicted insufficient weight gain, which was

Table 2 The relationship between major variables of the study, $(n=360)^{\mathrm{a}}$

\begin{tabular}{|c|c|c|c|c|c|}
\hline & Openness & Extraversion & Neuroticism & Conscientiousness & Agreeableness \\
\hline Total weight gain & -0.02 & -0.04 & -0.02 & -0.08 & -0.06 \\
\hline Birth weight & -0.05 & -0.07 & -0.1 & $-0.2^{* *}$ & -0.04 \\
\hline Grains & 0.05 & 0.07 & -0.08 & $0.11^{*}$ & 0.03 \\
\hline Dairy products & $0.11^{*}$ & 0.02 & $0.12^{*}$ & 0.06 & $-0.15^{* *}$ \\
\hline Proteins & -0.01 & 0.09 & -0.04 & 0.09 & 0.07 \\
\hline Fruits & -0.04 & -0.02 & -0.09 & $0.12^{*}$ & 0.06 \\
\hline Vegetables & $0.11^{*}$ & $0.22^{* * *}$ & $-0.25^{* * *}$ & $0.16^{* * *}$ & $0.13^{*}$ \\
\hline Sweets & 0.03 & 0.06 & $0.10^{*}$ & 0.04 & 0.01 \\
\hline Fats & 0.04 & $0.21^{* *}$ & $-0.11^{*}$ & $0.2^{* *}$ & 0.03 \\
\hline Emotional eating & $0.2^{* *}$ & $0.12^{*}$ & 0.07 & $0.18^{* *}$ & -0.02 \\
\hline Restrained eating & $0.12^{*}$ & $0.12^{*}$ & 0.05 & $0.11^{*}$ & -0.05 \\
\hline External. eating & $0.2^{* *}$ & $0.11 *$ & $0.10^{*}$ & $0.17^{* *}$ & -0.06 \\
\hline
\end{tabular}

a Presented as Pearson correlation coefficient $(r) ;{ }^{*} p<0.05 ;{ }^{* *} p<0.01$ 
Table 3 The mean and standard deviation of eating behavior scores, total and second half of pregnancy weight gain and birth weight of infants among different tertile groups of personality traits $(n=360)^{a}$

\begin{tabular}{|c|c|c|c|c|c|c|c|}
\hline & & $\begin{array}{l}\text { Restrained eating } \\
\text { (score) }\end{array}$ & $\begin{array}{l}\text { Emotional eating } \\
\text { (score) }\end{array}$ & $\begin{array}{l}\text { External eating } \\
\text { (score) }\end{array}$ & $\begin{array}{l}\text { Total weight gain } \\
(\mathrm{kg})\end{array}$ & $\begin{array}{l}\text { Second-half weight gain } \\
(\mathrm{kg})\end{array}$ & $\begin{array}{l}\text { Birth weight } \\
(\mathrm{kg})\end{array}$ \\
\hline $\begin{array}{l}\text { Personality } \\
\text { traits }\end{array}$ & $\mathrm{N}$ & Mean(SD) & & & & & \\
\hline \multicolumn{8}{|l|}{ Neuroticism } \\
\hline Low & 115 & $2.38(0.42)$ & 2.44(0.47)ab & $2.26(0.50) a$ & 12.33(3.35)a & 11.03(3.38)ab & $3.12(0.48) a b$ \\
\hline Moderate & 149 & $2.36(0.53)$ & $2.38(0.51) a$ & $2.27(0.50) a$ & $13.5(3.12) b$ & 11.94(3.09)a & $3.16(0.47) a$ \\
\hline high & 96 & $2.49(0.54)$ & $2.56(0.50) \mathrm{b}$ & $2.48(0.53) \mathrm{b}$ & 12.1(3.26)a & 10.57(3.24)b & $2.99(0.43) b$ \\
\hline$p$-value ${ }^{\#}$ & & 0.14 & $0.027^{* *}$ & $0.002^{* *}$ & $0.001^{* *}$ & $0.004^{* *}$ & $0.02^{*}$ \\
\hline \multicolumn{8}{|l|}{ Extraversion } \\
\hline Low & 100 & $2.45(0.54) a$ & 2.43(0.47)ab & $2.33(0.54)$ & $12.89(3.12)$ & $11.49(2.92)$ & $3.09(0.46)$ \\
\hline Moderate & 142 & $2.29(0.45) b$ & 2.36(0.49)a & $2.27(0.44)$ & $12.87(3.57)$ & 11.2(3.68) & $3.14(0.47)$ \\
\hline high & 118 & $2.50(0.51) \mathrm{a}$ & $2.56(0.51) \mathrm{b}$ & $2.39(0.58)$ & $12.51(3.07)$ & $11.21(3.04)$ & $3.06(0.51)$ \\
\hline$p$-value ${ }^{\#}$ & & $0.002^{* *}$ & $0.004^{* *}$ & 0.18 & 0.6 & 0.7 & 0.11 \\
\hline \multicolumn{8}{|l|}{ Openness } \\
\hline Low & 113 & $2.36(0.47) a$ & $2.28(0.42) a$ & 2.20(0.44)ab & $12.69(2.91)$ & $11.27(2.82)$ & $3.09(0.4)$ \\
\hline Moderate & 159 & 2.36(0.47)ab & $2.50(0.52) \mathrm{b}$ & $2.32(0.48) a$ & 13.03(3.46) & $11.36(3.45)$ & $3.15(0.43)$ \\
\hline high & 88 & $2.55(0.57) \mathrm{b}$ & $2.56(0.53) \mathrm{b}$ & $3.50(0.63) \mathrm{b}$ & $12.35(3.41)$ & $11.17(3.5)$ & $3.02(0.51)$ \\
\hline$p$-value ${ }^{\#}$ & & $0.007^{* *}$ & $0.001^{* *}$ & $0.001^{* *}$ & 0.2 & 0.9 & 0.18 \\
\hline \multicolumn{8}{|c|}{ Agreeableness } \\
\hline Low & 91 & $2.39(0.64)$ & $2.41(0.47)$ & $2.32(0.56)$ & $12.84(2.87)$ & $11.23(2.73)$ & $3.15(0.43)$ \\
\hline Moderate & 183 & $2.42(0.46)$ & $2.45(0.49)$ & $2.35(0.47)$ & $12.9(3.41)$ & 11.49(3.49) & $3.08(0.46)$ \\
\hline high & 86 & $2.38(0.43)$ & $2.46(0.54)$ & $2.29(0.57)$ & $12.36(3.43)$ & 10.9(3.31) & $3.11(0.51)$ \\
\hline$p$-value ${ }^{\#}$ & & 0.74 & 0.75 & 0.71 & 0.4 & 0.38 & 0.49 \\
\hline \multicolumn{8}{|c|}{ Conscientiousness } \\
\hline Low & 90 & 2.38(0.52)ab & $2.44(0.46) a$ & 2.27(0.49)ab & 12.79(3.18)ab & $11.28(2.98)$ & $3.25(0.43) a$ \\
\hline Moderate & 170 & $2.34(0.47) a$ & $2.31(0.48) a b$ & $2.24(0.51) a$ & 13.13(3.29)a & 11.52(3.29) & $3.18(0.46) a$ \\
\hline high & 100 & $2.54(0.51) b$ & $2.68(0.47) b$ & $2.52(0.50) \mathrm{b}$ & 12.09(3.29)b & $10.88(3.47)$ & $2.96(0.48) b$ \\
\hline$p$-value ${ }^{\#}$ & & $0.005^{* *}$ & $0.001^{* *}$ & $0.001^{* *}$ & $0.04^{*}$ & 0.3 & $0.001^{* *}$ \\
\hline
\end{tabular}

${ }^{\mathrm{a}}$ Data are presented as Mean (SD), ${ }^{\#}$ One way ANOVA, ${ }^{*} p<0.05,{ }^{* *} p<0.01$, Tukey post hoc analysis was done and different letters indicated the significant difference

inconsistent with data from non-pregnant extraversion women, who had a positive association with overweightness and an inverse association with underweight [34]. Another study on women 30-54 years of age from general population has reported higher scores of extraversion to be associated with obesity [35]. Extraverts are impulsive and expressive and we found them to be more emotional eaters. Also we found that emotional eating predicted more insufficient weight gain. A study conducted on obese people showed a relationship between emotional eating with lower extraversion [36]. Although this study was conducted in a different population, it seems that hormonal and psychological changes during pregnancy have effect on the extraversion ones since it could be implied that emotional eating during pregnancy was accompanied with non-proper food choices which led to insufficient weight gain, among extravert-emotional eater pregnant subjects.

The present study showed the positive relationship of conscientiousness with restrained eating behavior, in contrast with other studies $[28,36]$. In addition, subjects in the third tertile of conscientiousness were gained the lower weight. Our results were in line with previous study that revealed people with low score of conscientiousness, gained more weight [37]. It seems the positive relationship between restrained eating behavior and conscientiousness is associated with the lower weight gain among the most conscientious subjects of our study.

In this study, women with high scores of neuroticism had a tendency to gain less weight, in line with another study in which neuroticism had an inverse association with overweightness [34]. Another study, however 
Table 4 Multinomial logistic regression for analysis of the associations of personality traits, eating behaviors and food intake with weight gain during pregnancy and neonatal birth weight $(n=360)$

\begin{tabular}{|c|c|c|c|c|c|c|c|c|c|c|c|c|}
\hline & \multicolumn{4}{|c|}{ Total weight gain } & \multicolumn{4}{|c|}{ Second half weight gain } & \multicolumn{4}{|c|}{ Birth weight } \\
\hline & \multicolumn{4}{|c|}{ Insufficient $^{a}$} & \multicolumn{4}{|c|}{ Insufficient $^{a}$} & \multicolumn{4}{|l|}{$\overline{\text { Low }^{a}}$} \\
\hline & $\bar{B}$ & $p$ & OR & $\mathrm{Cl}$ & $\bar{B}$ & $p$ & OR & $\mathrm{Cl}$ & $\mathrm{B}$ & $p$ & OR & $\mathrm{Cl}$ \\
\hline \multicolumn{13}{|l|}{ Personality } \\
\hline Neuroticism & -0.023 & 0.212 & 1.04 & $0.98-1.09$ & -0.023 & 0.631 & 0.98 & $0.89-1.07$ & 0.045 & 0.115 & 1.05 & $0.99-1.10$ \\
\hline Extraversion & 0.049 & 0.238 & 1.05 & $0.97-1.14$ & 0.162 & 0.015 & 1.18 & $1.03-1.34$ & 0.023 & 0.582 & 1.02 & $0.94-1.11$ \\
\hline Openness & 0.059 & 0.220 & 1.06 & $0.97-1.12$ & -0.169 & 0.051 & 0.84 & $0.71-1.01$ & 0.043 & 0.372 & 1.04 & $0.95-1.15$ \\
\hline Agreeableness & 0.010 & 0.835 & 1.01 & $0.918-1.12$ & -0.034 & 0.680 & 0.97 & $0.82-1.14$ & 0.058 & 0.237 & 1.06 & $0.96-1.16$ \\
\hline Conscientiousness & 0.073 & 0.197 & 1.08 & $0.96-1.20$ & -0.053 & 0.586 & 0.95 & $0.78-1.15$ & 0.183 & 0.001 & 1.20 & $1.07-1.34$ \\
\hline \multicolumn{13}{|l|}{ Eating behavior } \\
\hline Restrained eating & -0.056 & 0.920 & 0.95 & $0.32-2.82$ & -0.891 & 0.338 & 0.41 & $0.07-2.54$ & -0.632 & 0.241 & 0.53 & $0.18-1.52$ \\
\hline Emotional eating & 1.098 & 0.034 & 2.99 & $1.08-8.28$ & 0.80 & 0.372 & 2.22 & $0.38-12.8$ & 1.366 & 0.008 & 3.92 & $1.43-10.74$ \\
\hline External eating & -0.948 & 0.103 & 0.39 & $0.12-1.21$ & -0.706 & 0.50 & 0.59 & $0.6-3.84$ & -0.145 & 0.802 & 0.86 & $0.28-2.68$ \\
\hline \multicolumn{13}{|l|}{ Food intake } \\
\hline Grains & 0.08 & 0.062 & 1.08 & $0.99-1.18$ & 0.034 & 0.653 & 1.03 & $0.89-1.20$ & 0.049 & 0.244 & 1.05 & $0.97-1.14$ \\
\hline Dairy products & -0.033 & 0.696 & 0.97 & $0.82-1.14$ & -0.159 & 0.331 & 0.85 & $0.62-1.17$ & -0.023 & 0.780 & 0.98 & $0.83-1.15$ \\
\hline Proteins & 0.011 & 0.862 & 1.01 & $0.89-1.15$ & 0.204 & 0.089 & 1.23 & $0.97-1.55$ & 0.045 & 0.480 & 1.05 & $0.92-1.19$ \\
\hline Vegetables & -0.399 & 0.023 & 0.67 & $0.47-0.95$ & -0.83 & 0.006 & 0.41 & $0.22-0.77$ & -0.325 & 0.057 & 0.72 & $0.51-1.00$ \\
\hline Fruits & -0.067 & 0.676 & 0.93 & $0.68-1.28$ & -0.154 & 0.595 & 0.86 & $0.49-1.51$ & 0.084 & 0.59 & 1.09 & $0.80-1.47$ \\
\hline Fats & -0.023 & 0.938 & 0.97 & $0.55-1.73$ & 1.384 & 0.018 & 3.99 & $1.27-12.5$ & -0.041 & 0.886 & 0.96 & $0.55-1.69$ \\
\hline Sweets & -0.013 & 0.949 & 0.99 & $0.66-1.47$ & -0.072 & 0.837 & 0.93 & $0.47-1.85$ & 0.215 & 0.260 & 1.24 & $0.85-1.80$ \\
\hline
\end{tabular}

${ }^{a}$ The reference category is adequate; $B$ beta; $p$ p-value; $O R$ odds ratio; $C l$ confidence interval. The effects of maternal age, pre-pregnancy body mass index and length of gestation were adjusted

showed no association between neuroticism and obesity [35]. The results of our study confirmed a negative correlation between frequency intake of vegetables and the score of neuroticism, and less frequent intake of vegetables (as a representative of healthy diet) predicted insufficient weight gain. Another finding was that high scores of neuroticism were related to high scores of emotional and external eating, and in this study, emotional eating predicted insufficient weight gain. Then it could be explained why neurotic women experienced lower weight gain during pregnancy. The finding of this study, showed unexpected results about some types of personality, eating behaviors and weight gain during pregnancy, when they compare with other studies which were conducted on general population or obese people [36]. Although some other studies found no relationship between any eating behavior and gestational weight gain [33]. In the meantime, other studies, showed less restrained eating behavior during pregnancy but it had not any relationship with weight gain [38]. So it would be interesting to compare the relationship between eating behaviors, different food intakes and weight gain, at pre-pregnancy state and during pregnancy, in future studies.

Here we would have a look on our findings about food intake and weight gain. We showed that a more frequent intake of fat could predict insufficient weight gain; inconsistent with findings in other studies which showed that fried foods were directly associated with excessive weight gain [39]. In contrast, our findings revealed that decreased frequency intake of vegetables might predict insufficient weight gain. Other studies did not observe any risk of excessive gestational weight gain in relation to consumption of vegetables [39-41]. It could be explained that a more frequent intake of vegetables and a less frequent intake of fats or sweets, are more appropriate and would result in adequate weight gain.

\section{Personality trait, eating behavior and neonatal birth weight}

To the best of our knowledge, to date, two studies on general population and couples have assessed all the FFM domains and changes in BMI over a period of time $[7,25]$ and our study is the first to explore the association between the personality traits with gestational weight gain. It is also the first one dealing with the way FFM contributes to key criteria of birth weight. The results indicated lower birth weight of infants among mothers with high score of neuroticism and conscientiousness personality traits. Apparently, this finding is related to maternal weight gain because mothers with 
high score of neuroticism or conscientiousness experienced less weight gain.

\section{Strengths and limitation of the study}

The limitation of the study was the employment of multiple questionnaires to be filled by the participants, which might have been boring them. Therefore, it was difficult to use a long food frequency questionnaire to determine dietary pattern. Also, different delivery times among the subjects forced the researchers to record birth weights only from infants' health cards rather than weighting the infants themselves. Finding the association of personality traits with maternal weight gain and birth weight of infants, was the major point of the study. However, it would be suggested to evaluate gestational growth in the second and third trimester and hematochemical parameters, as additional variables in future studies. Another important point was the use of a dietary food intake questionnaire in accordance with Iranian food guide pyramid to evaluate the consumption of major components of food groups and subgroups. Most of the previous studies, however, only reported the association of energy intake during pregnancy with gestational weight gain. Also, this research was done as a longitudinal study in which the subjects were followed from the second half of their pregnancy until delivery.

\section{Conclusion}

The findings of the study revealed the relationship of personality trait with weight gain during pregnancy. It seems identification of the individual personality traits can have positive effect on health and nutritional education especially during the important periods of life such as pregnancy and lactation. Thus this could be studied as a new approach in nutritional consultation during pregnancy, in future. In this regard, studying the eating behaviors and food pattern before pregnancy and their changes during pregnancy, may be helpful in identifying the exact relationship between eating behaviors and personality traits at pregnancy.

\section{Abbreviations}

ANOVA: One-way Analysis of Variances; BMI: Body Mass Index; DEBQ: Dutch Eating Behavior Questionnaire; FFM: Five-Factor Model; FFQ: Food Frequency Questionnaire; IOM: Institute of Medicine; NEO-FFI: NEO Five-Factor Inventory; SD: Standard Deviation

\section{Acknowledgments}

The authors greatly appreciate Dr. Aryo Zare for his valuable comments and suggestions. The authors thank to the pregnant women who participated in the study.

\section{Authors' contributions}

MS: Drafting the article and data acquisition.SJ: Substantial contributions to conception and design, supervising the study and revising the article critically for important intellectual content. RA: Substantial contributions to conception and design. BC: Data analysis and interpretation. MN: Substantial contributions to conception and design. All authors approved the final manuscript.

\section{Funding}

This study was a part of the Master's thesis of Mahboobeh Shakeri and was registered in the Nutrition and Metabolic Diseases Research Center. The Vice Chancellor for research affairs of Ahvaz Jundishapur University of Medical Sciences supported the study (NRC-9419).

\section{Availability of data and materials}

Data of the present research is available by contacting the corresponding author on reasonable request.

\section{Ethics approval and consent to participate}

This study was conducted according to the guidelines laid down in the Declaration of Helsinki and all procedures involving human subjects were approved by the Ethics Committee of Ahvaz Jundishapur University of Medical Sciences (ID: IR.AJUMS.REC.1394.609). All subjects provided written and informed consent and were reassured that their information will be kept confidential.

\section{Consent for publication}

Not applicable

\section{Competing interests}

The authors declare that they have no conflict of interest.

\section{Author details}

${ }^{1}$ Nutrition and Metabolic Diseases Research Center, Ahvaz Jundishapur University of Medical Sciences, Ahvaz, Iran. ${ }^{2}$ Department of Nutrition, School of Allied Medical Sciences, Ahvaz Jundishapur University of Medical Sciences, Ahvaz, Iran. ${ }^{3}$ Food Security Research Center, Department of Clinical Nutrition, School of Nutrition and Food Science, Isfahan University of Medical Sciences, Isfahan, Iran. ${ }^{4}$ Health Research Institute, Diabetes Research Center, Ahvaz Jundishapur University of Medical Sciences, Ahvaz, Iran. ${ }^{5}$ Department of Epidemiology and Biostatistics, School of Health, Ahvaz Jundishapur University of Medical Sciences, Ahvaz, Iran. ${ }^{6}$ Department of Obstetrics \& Gynecology, School of Medicine, Ahvaz Jundishapur University of Medical Sciences, Ahvaz, Iran.

Received: 24 March 2020 Accepted: 29 June 2020

Published online: 06 July 2020

\section{References}

1. Deary IJ, Weiss A, Batty GD. Intelligence and personality as predictors of illness and death how researchers in differential psychology and chronic disease epidemiology are collaborating to understand and address health inequalities. Psychol Sci Public Interest. 2010;11(2):53-79.

2. Goodwin RD, Friedman HS. Health status and the five-factor personality traits in a nationally representative sample. J Health Psychol. 2006;11(5):64354.

3. Chapman BP, Khan A, Harper M, et al. Gender, race/ethnicity, personality, and interleukin-6 in urban primary care patients. Brain Behav Immun. 2009; 23(5):636-42.

4. Sutin AR, Terracciano A, Deiana B, et al. High neuroticism and low conscientiousness are associated with interleukin-6. Psychol Med. 2010; 40(09):1485-93.

5. Chapman BP, Duberstein PR, Sörensen $S$, et al. Gender differences in five factor model personality traits in an elderly cohort. Personal Individ Differ. 2007:43(6):1594-603.

6. Chapman BP, Lyness JM, Duberstein P. Personality and medical illness burden among older adults in primary care. Psychosom Med. 2007;69(3): 277-82.

7. Sutin $A R$, Ferrucci $L$, Zonderman $A B$, et al. Personality and obesity across the adult life span. J Pers Soc Psychol. 2011;101(3):579-92.

8. Terracciano A, Costa PT. Smoking and the five-factor model of personality. Addiction. 2004:99(4):472-81.

9. Schutte NS, Malouff JM, Thorsteinsson EB, et al. A meta-analytic investigation of the relationship between emotional intelligence and health Personal Individ Differ. 2007;42(6):921-33. 
10. Terracciano A, Löckenhoff CE, Crum RM, et al. Five-factor model personality profiles of drug users. Bmc Psychiatry. 2008;8(1):22.

11. Rhodes R, Smith N. Personality correlates of physical activity: a review and meta-analysis. Br J Sports Med. 2006:40(12):958-65.

12. Bogg T, Roberts BW. Conscientiousness and health-related behaviors: a meta-analysis of the leading behavioral contributors to mortality. Psychol Bull. 2004;130(6):887-919.

13. Hoyt AL, Rhodes RE, Hausenblas HA, et al. Integrating five-factor model facet-level traits with the theory of planned behavior and exercise. Psychol Sport Exerc. 2009;10(5):565-72.

14. McCrae RR, Costa PT. A contemplated revision of the NEO five-factor inventory. Personal Individ Differ. 2004;36(3):587-96.

15. Saucier G, Goldberg LR. Lexical studies of indigenous personality factors: premises, products, and prospects. J Pers. 2001;69(6):847-79.

16. Hendriks AAJ, Perugini M, Angleitner A, et al. The five-factor personality inventory: cross-cultural generalizability across 13 countries. Eur J Personal. 2003;17(5):347-73.

17. John O, Srivastava S. The Big Five trait taxonomy: History, measurement, and theoretical perspectives. In: Pervin LA, John OP, editors. Handbook of personality: Theory and research. 2nd ed. New York: Guilford Press; 1999. p. 102-38.

18. Caspi A, Roberts BW, Shiner RL. Personality development: stability and change. Annu Rev Psychol. 2005;56:453-84.

19. Gerlach G, Herpertz S, Loeber S. Personality traits and obesity: a systematic review. Obes Rev. 2015;16(1):32-63.

20. Mõttus R, Realo A, Allik J, et al. Personality traits and eating habits in a large sample of Estonians. Health Psychol. 2012;31(6):806-14.

21. Mõttus R, McNeill G, Jia X, et al. The associations between personality, diet and body mass index in older people. Health Psychol. 2013;32(4):353-60.

22. Mela DJ. Determinants of food choice: relationships with obesity and weight control. Obes Res. 2001;9(S4):249S-55S.

23. Mohammadi M, Amir AliAkbari S, Mohammadi F, et al. Weight gain and food group consumption patterns in pregnant women of north and east hospitals of Tehran. Iran J Endocrinol Metab. 2011;12(6):609-17.

24. Rasmussen KM, Yaktine AL. Committee to reexamine IOM pregnancy weight guidelines. Food and nutrition board, board on children, youth and families, Institute of Medicine, National Research Council. Weight gain during pregnancy: reexamining the guidelines. Washington, DC: National Academies Press; 2009

25. Chu SY, Callaghan WM, Bish $C L$, et al. Gestational weight gain by body mass index among US women delivering live births, 2004-2005: fueling future obesity. Am J Obstetrics Gynecol. 2009;200(3):271 e1-. e7.

26. Webb JB, Siega-Riz AM, Dole N. Psychosocial determinants of adequacy of gestational weight gain. Obesity. 2009;17(2):300-9.

27. Kapadia MZ, Gaston A, Van Blyderveen S, et al. Psychological factors and trimester-specific gestational weight gain: a systematic review. J Psychosom Obstet Gynecol. 2015;36(1):15-22.

28. Keller C, Siegrist M. Does personality influence eating styles and food choices? Direct and indirect effects. Appetite. 2015;84:128-38.

29. Roh S-J, Kim H-N, Shim U, et al. Association between blood lipid levels and personality traits in young Korean women. PLoS One. 2014;9(9):e108406.

30. Van Strien T, Frijters JE, Bergers G, et al. The Dutch eating behavior questionnaire (DEBQ) for assessment of restrained, emotional, and external eating behavior. Int J Eat Disord. 1986;5(2):295-315.

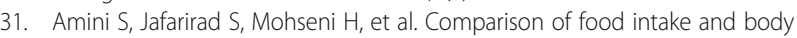
mass index before pregnancy between women with spontaneous abortion and women with successful pregnancy. Iran J Obstetrics Gynecol Infertility. 2017;20(10):35-42.

32. Ghaffarpour M, Houshiar-Rad A, Kianfar H. The manual for householdmeasures, cooking yields factors and edible portion of food. Tehran: Keshaverzi press; 1999.

33. Van der Wijden $\mathrm{CL}$, Steinbach S, van der Ploeg HP, et al. A longitudinal study on the relationship between eating style and gestational weight gain. Appetite. 2014;83:304-8.

34. Kakizaki M, Kuriyama S, Sato $Y$, et al. Personality and body mass index: a cross-sectional analysis from the Miyagi cohort study. J Psychosom Res. 2008;64(1):71-80.

35. Hällström T, Noppa H. Obesity in women in relation to mental illness, social factors and personality traits. J Psychosom Res. 1981;25(2):75-82.

36. Elfhag K, Morey LC. Personality traits and eating behavior in the obese: poor self-control in emotional and external eating but personality assets in restrained eating. Eat Behav. 2008;9(3):285-93.
37. Brummett BH, Siegler IC, Day RS, et al. Personality as a predictor of dietary quality in spouses during midlife. Behav Med. 2008;34(1):5-10.

38. Clark $M$, Ogden J. The impact of pregnancy on eating behaviour and aspects of weight concern. Int J Obes. 1999;23(1):18-24.

39. Stuebe AM, Oken E, Gillman MW. Associations of diet and physical activity during pregnancy with risk for excessive gestational weight gain. Am J Obstetrics Gynecol. 2009;201(1):58 e1-. e8.

40. Johnson J, Clifton RG, Roberts JM, et al. Pregnancy outcomes with weight gain above or below the 2009 Institute of Medicine guidelines. Obstet Gynecol. 2013;121(5):969-75.

41. Kinnunen $T$, Pasanen $M$, Aittasalo $M$, et al. Preventing excessive weight gain during pregnancy-a controlled trial in primary health care. Eur J Clin Nutr. 2007;61(7):884-91.

\section{Publisher's Note}

Springer Nature remains neutral with regard to jurisdictional claims in published maps and institutional affiliations.
Ready to submit your research? Choose BMC and benefit from:

- fast, convenient online submission

- thorough peer review by experienced researchers in your field

- rapid publication on acceptance

- support for research data, including large and complex data types

- gold Open Access which fosters wider collaboration and increased citations

- maximum visibility for your research: over $100 \mathrm{M}$ website views per year

At BMC, research is always in progress.

Learn more biomedcentral.com/submission 